\title{
Sustainable road bases with microbial precipitation
}

\author{
Hannah Porter BEng \\ PhD Scholar, Department of Civil Engineering, Curtin University, Bentley, \\ WA, Australia \\ Navdeep Kaur Dhami PhD \\ Research Fellow, Department of Civil Engineering, Curtin University, \\ Bentley, WA, Australia
}

\author{
Abhijit Mukherjee PhD \\ Professor of Civil Engineering, Department of Civil Engineering, \\ Curtin University, Bentley, WA, Australia (corresponding author: \\ abhijit.mukherjee@curtin.edu.au) (Orcid:0000-0001-6972-8962)
}

The Australian road network is nearly a million kilometres long, of which $83 \%$ can be classified as rural roads. The size and remote nature of Australia's road network pose unique challenges in terms of asset monitoring and maintenance costs. Cement stabilisation is a practice commonly used to improve durability and reduce inspection and repair costs. However, due to the sheer length of the road network, a huge quantity of cement is consumed in stabilisation work, making this practice unsustainable. This paper explores a sustainable alternative through augmentation of the traditional cement-based stabilisation with microbial carbonate precipitation. The calcium carbonate crystals formed within the samples were investigated by scanning electron microscopy and X-ray diffraction. Bulk mechanical properties were characterised through unconfined compressive strength (UCS) testing and the digital image correlation technique was utilised during UCS testing to extract more refined information such as local deformation and strain build-up. The mechanical properties at the microscopic scale were characterised through nanoindentation testing. The results show that microbial precipitation is able to increase the strength of cement-stabilised and road base materials significantly and can considerably improve the technological, economic and social sustainability of Australian road bases.

\section{Introduction}

Australia is a continent with sparse population density. Connecting remote locations with a road network has resulted in the country having the highest road length per capita. The Australian road network comprises $873573 \mathrm{~km}$ of roads, of which $83 \%$ can be classified as rural roads (DoIRD, 2015). Such a vast and remote road network creates a formidable problem in terms of monitoring the deterioration in pavement structures as well as the identification and prioritisation of maintenance and rehabilitation works. In the past 10 years (2005-2015), Australia has spent \$21 billion on road and bridge maintenance works (DoIRD, 2015). Understandably, a durable road base system that would minimise the need for frequent inspection and maintenance has been opted for. Cement stabilisation is a practice commonly followed in the Australian road industry for ensuring the adequate strength and stiffness of a granular road base material. According to Austroads (2006), it is common for the cost of the binder material (cement) in stabilisation works to be $\sim 40 \%$ or more of the total cost of the works. Typical energy consumption rates for cement-stabilised materials have been estimated to be $\sim 5000 \mathrm{MJ} / \mathrm{t}$ while the actual placement and construction of the stabilised road base is estimated to result in a rate of consumption of only $50 \mathrm{MJ} / \mathrm{t}$ (Austroads, 2007). Although the present road base has proved to be very functional, the mandate to develop sustainable technologies necessitates drastically limiting energy consumption and emissions. Evidently, a sustainable binder for road base material with dramatically lower embodied energy and emission must be developed.

The Australian landscape has a large number of sustainable natural formations such as ant hills, corals and stromatolites. These structures also bind granular materials while using negligible embodied energy. Recent research has revealed the role of microbes in cementing natural formations such as stalagmites, stromatolites and corals (Chen et al., 2012). The process of natural cementation has been emulated in laboratory protocols known as microbially induced calcium carbonate $\left(\mathrm{CaCO}_{3}\right)$ precipitation (MICP) (Stocks-Fischer et al., 1999). MICP is a form of bio-mineralisation where the metabolic products of microbes result in the precipitation of calcium carbonate in the presence of an ionic calcium carbon source (Castanier et al., 1999). During urea hydrolysis, bacteria within soil metabolise urea and produce ammonia $\left(\mathrm{NH}_{3}\right)$ and carbon dioxide $\left(\mathrm{CO}_{2}\right)$ within the cell (Reaction I). These chemicals diffuse through the bacterial cell wall into the surrounding pore space between soil grains. The ammonia reacts with water $\left(\mathrm{H}_{2} \mathrm{O}\right)$ to produce ammonium cation $\left(\mathrm{NH}_{4}^{+}\right)$and hydroxyl ions $\left(\mathrm{OH}^{-}\right)$(Reaction II) resulting in a corresponding increase in the $\mathrm{pH}$ of the solution while the carbon dioxide equilibrates to form bicarbonate $\left(\mathrm{HCO}_{3}\right)$ (Reaction III). In the presence of introduced calcium 
(attracted to the bacterial cell walls), the bicarbonate then reacts with the hydroxyl ions to precipitate calcium carbonate (Reaction IV).

I. $\mathrm{NH}_{2}-\mathrm{CO}-\mathrm{NH}_{2}+\mathrm{H}_{2} \mathrm{O} \rightarrow 2 \mathrm{NH}_{3}+\mathrm{CO}_{2}$

II. $2 \mathrm{NH}_{3}+2 \mathrm{H}_{2} \mathrm{O} \rightarrow 2 \mathrm{NH}_{4}^{+}+2 \mathrm{OH}^{-}$

III. $\mathrm{CO}_{2}+\mathrm{OH}^{-} \rightarrow \mathrm{HCO}_{3}$

IV. $\mathrm{Ca}^{2+}+\mathrm{HCO}_{3}+\mathrm{OH}^{-} \rightarrow \mathrm{CaCO}_{3}+\mathrm{H}_{2} \mathrm{O}$

The most remarkable feature of MICP is that, unlike traditional cement, the bio-cement is produced under ambient conditions with water as the solvent. It thus obviates the consumption of energy in cement manufacturing (Achal et al., 2015). Mitchell and Santamarina (2005) report that a kilogram of soil has nearly $10^{12}$ microbes and many of them can be classified as calcifying. Thus, it is possible to harness the calcifying bacteria present in the soil of road bases for cementation action. MICP is an emerging technology for various geotechnical applications (DeJong et al., 2014). It has also proved to be a very attractive measure to improve the engineering properties of all building materials (Achal and Mukherjee, 2015). During the process of MICP, bacteria within the soil digest nutrients and precipitate calcium carbonate. There are several different biological processes that can cause calcium carbonate precipitation to occur; however, the process that occurs the fastest, and requires the least free energy, is precipitation by means of urea hydrolysis (DeJong et al., 2010).

Laboratory experiments have demonstrated the potential of MICP in the improvement of soil strength (Ferris et al., 1996; Le Métayer-Levrel et al., 1999; Whiffin et al., 2007), reduction of permeability (Harkes et al., 2010), stabilisation of slopes (DeJong et al., 2010; Harkes et al., 2010), improved resistance to liquefaction (Burbank et al., 2011) and also suppression of dust (Chu et al., 2012). MICP forms 'cohesive bridges' between the grains of sand through the deposition of calcium carbonate crystals that increase the stiffness of the material and also reduce its permeability (Van Paassen et al., 2010). MICP was found to resist the deterioration of concrete in freeze-thaw, sulfate attack and drying shrinkage (Ramachandran et al., 2001). In the case of reinforced concrete, MICP retards moisture and chloride ion diffusion and the corrosion of steel (Dhami et al., 2012a). Much progress has been made in unravelling the biochemical processes (Bains et al., 2015; Castanier et al., 1999; Ercole et al., 2012) and in improving the bacterial strains (Achal et al., 2009a; Bergdale et al., 2012), the use of industrial by-products (Achal et al., 2009b; Dhami et al., 2012b) and process optimisation (Dhami et al., 2016a; Okyay and Rodrigues, 2015). After the success of laboratory-scale experiments, in situ soil strengthening in the field (bio-grouting) has been attempted where biological fluid is injected in the soil. It has been observed that although the technique works well for surface treatments, coarse-grained materials and mixed-in-place applications, in the case of finegrained materials the injection well clogs rapidly (Le MétayerLevrel et al., 1999). The optimal pressure to avoid clogging has been investigated and it was observed that a flow rate of $350 \mathrm{ml} / \mathrm{h}$ could avoid the clogging of a $5 \mathrm{~m}$ long tube (Whiffin et al., 2007). Van Paassen et al. (2010) observed that in largescale experiments (treatment volume of up to $100 \mathrm{~m}^{3}$ ), the use of bio-grouting is technically feasible under conditions common to those found in practice (Van Paassen et al., 2009). Large-scale laboratory tests on dike reinforcement using biocementation have already been carried out. Burbank et al., (2011) reported the formation of around 1\% calcium carbonate in near-surface and $1 \cdot 8-2 \cdot 4 \%$ calcite $<90 \mathrm{~cm}$ after stimulating indigenous ureolytic microbes in soils on the shore of the Snake River, USA.

Although MICP has shown much promise, the field trials must be implemented in a phased manner. Thus, it is advisable to apply MICP in Australian road bases in addition to cement stabilisers. Some challenges in the compatibility between cement-stabilised soil and MICP are envisaged. The MICP process, on the one hand, may impose restrictions on the control of moisture in soil to achieve the optimal consolidation; on the other hand, it may be affected by the high $\mathrm{pH}$ of cement. This paper reports the performance of MICP as a stabilising technique on its own and as an augmentation to cement-stabilised road base materials. It is noted that pre-stabilisation with a cement binder increases the carbonate precipitation of carbonates at inter-granular bridges and thus a small quantity of carbonate crystals improves the strength considerably. This was evident through the combined results of strength testing, scanning electron microscopy (SEM) and nanoindentation. Unconfined compressive strength (UCS) results showed a greater improvement in the combined MICP/cement system than the strength increase obtained through MICP or cement stabilisation alone, while micrographs of the granular structure showed cement evenly coating the soil grains and carbonate crystals precipitating at the bridges between particles. Nanoindentation testing conducted on the samples revealed that MICP treatment on cement-stabilised samples increased the stiffness of cementitious bridges between particles and at the sand/bridge interface to a value greater than that obtained for samples treated with only MICP (SM) or only cement (SC). Through digital image correlation (DIC), the deformation and strain build-up at the time of performing UCS 
tests were monitored. It was discovered that DIC is able to pinpoint the local strain build-up at early stages of loading. These locations ultimately cause cracking and collapse. Evidently, DIC has the potential to be a convenient technique for the early identification of deterioration in road surfaces and a useful road asset-management tool.

\section{Experimental and methods}

In this investigation, standard methods of testing cementstabilised samples and modified ones with MICP were followed. In the case of standard samples, maximum compaction was achieved by maintaining an optimal moisture content (OMC) and the standard compaction technique on a sample of standard size. In the case of MICP stabilisation, the addition of cementation fluid violates the OMC conditions. Preparation of standard (100 mm diameter) MICP-treated samples is also difficult under laboratory conditions. Thus, samples of three sizes were prepared (Table 1). SC100 were standard samples in terms of size, moisture content and compaction. SC65 were intermediate-scale samples while SC30 samples were the smallest where neither the OMC nor the compaction were maintained. Such samples are amenable to MICP. However, MICP has been tried hitherto in sand only and not in road base materials. Therefore, both sand and road base materials were investigated for MICP. The samples were tested for UCS with DIC. Their microstructure was studied by
SEM and energy dispersive X-ray spectroscopy (EDS) and their mechanical performance at the micro scale was investigated using nanoindentation.

\subsection{Materials}

Manufactured sand sourced from Cook Industrial Minerals, Perth, Western Australia was used as the granular component of samples SC100, SC65, SC, SM and SCM (samples stabilised with combined cement and MICP). The sand can be classified as medium-graded sand in accordance with ISO 14688 (ISO, 2002). Road base material was provided by the Department of Transport and Main Roads, West Australia and was used for samples R, RM, RC and RCM (see Table 1). Road base material was sourced from Graham Pit, located $\sim 5 \mathrm{~km}$ from the township of Narrogin. Commercially available general-purpose grey cement sourced from Swan Cement, Perth, complying with AS 3972 (SA, 2010) and standard tap water were also utilised.

Two ureolytic strains of bacteria were used for the MICPtreated samples. In the case of sand samples, the bacterial strain Bacillus cereus (ATCC 11778) was used. The bacteria were grown in a nutrient broth growth media as detailed in Table 2. The bacteria were grown at a temperature of $37^{\circ} \mathrm{C}$ at $200 \mathrm{r} / \mathrm{min}$ for $24-36 \mathrm{~h}$. The optical density of the bacterial solution at harvesting varied between $5 \times 10^{7}$ and $8 \times 10^{8} \mathrm{cfu} / \mathrm{ml}$.

Table 1. Details of samples

$\begin{array}{llccc}\text { Identifier } & \text { Description } & \text { Diameter: } \mathbf{~ m m} & \text { Height: } \mathbf{m m} & \text { Repeats } \\ \text { SC100 } & \text { Sand + 7\% cement } & 100 & 200 & 3 \\ \text { SC65 } & \text { Sand + 7\% cement } & 65 & 130 & 2 \\ \text { SC } & \text { Sand + 7\% cement } & 30 & 60 & 3 \\ \text { SM } & \text { Sand + MICP } & 30 & 60 & 3 \\ \text { SCM } & \text { Sand + 7\% cement + MICP } & 30 & 60 & 3 \\ \text { R } & \text { Road base } & 30 & 60 & 3 \\ \text { RM } & \text { Road base + MICP } & 30 & 60 & 3 \\ \text { RC } & \text { Road base + 5\% cement } & 30 & 60 & 3 \\ \text { RCM } & \text { Road base + 5\% cement + MICP } & 30 & 60 & 3\end{array}$

Table 2. Materials for MICP treatment on sand samples

$\begin{array}{lll}\text { Description } & \text { Material } & \text { Concentration } \\ \text { Microbial growth media } & \text { B. cereus (ATCC 11778) isolate } & 5 \times 10^{7}-8 \times 10^{8} \mathrm{cfu} / \mathrm{ml} \\ & \text { Bacto nutrient broth } & 13 \mathrm{~g} / \mathrm{l} \\ & \text { Nickel sulfate } & 1 \mathrm{mM} \\ & \text { Urea } & 0.05 \mathrm{M} \\ \text { Cementation solution } & \text { Tris buffer (pH 8.4) } & 0.15 \mathrm{M} \\ & \text { Urea } & 0.5 \mathrm{M} \\ & \text { Calcium chloride } & 0.5 \mathrm{M} \\ \end{array}$


Table 3. Materials for MICP treatment on road base samples

\begin{tabular}{lll}
\hline Description & Material & Concentration \\
\hline Microbial growth media & S. pasteurii (ATCC & $1 \times 10^{9} \mathrm{cfu} / \mathrm{ml}$ \\
& 11859) isolate & \\
& Yeast extract & $20 \mathrm{~g} / \mathrm{l}$ \\
& Ammonium sulfate & $10 \mathrm{~g} / \mathrm{l}$ \\
& Nickel chloride & $2 \mu \mathrm{M}$ \\
& Tris buffer (pH 9) & $0.15 \mathrm{M}$ \\
Cementation solution & Urea & $0.5 \mathrm{M}$ \\
& Calcium chloride & $0.5 \mathrm{M}$ \\
& Yeast extract & $0.5 \mathrm{~g} / \mathrm{l}$ \\
& &
\end{tabular}

In the case of the road base samples, Sporosarcina pasteurii (ATCC 11859) was used for MICP treatment. The bacteria were inoculated in an ammonium-yeast extract media as described by Bernardi et al. (2014) and detailed in Table 3 . The bacteria were grown at a temperature of $37^{\circ} \mathrm{C}$ at $200 \mathrm{r} / \mathrm{min}$ for 24-36 h until a concentration of $1 \times 10^{9} \mathrm{cfu} / \mathrm{ml}$.

After compaction, the microbially treated samples were cured for $20 \mathrm{~d}$ in an incubator at a temperature of $37^{\circ} \mathrm{C}$. Each day, one pore volume of cementation solution was added to the top of samples and allowed to filter through to the outlet at the bottom of the sample by means of gravity. The cementation solution was autoclaved prior to adding the urea component. After autoclaving, the solution was stabilised to a $\mathrm{pH}$ of between 8.0 and $8 \cdot 5$. The cementation solution for MICP-treated sand and road base samples is detailed in Tables 2 and 3 .

\subsubsection{Particle size distribution}

To characterise the particle size distribution of the two mixes, a sieve analysis was conducted in accordance with the requirements of AS 1289.3.6.1 (SA, 2009). The particle size distribution for the manufactured sand and the road base mix is shown in Figure 1. The sand had a much narrower distribution of grain size than that of the road base, which contained a considerable amount of large aggregates.

\subsection{Sample preparation}

The standard SC100 samples were prepared in three steps: finding out the maximum dry density (MDD), preparing the samples through compaction and curing them. Cement was added at a proportion of $7 \%$ (by mass) of sand. The MDD of the cement-sand mixtures was obtained by finding the OMC according to AS 1289.5.2.1 (SA, 2003). An OMC of $10 \%$ by mass was found to achieve a MDD of $1.6 \mathrm{~g} / \mathrm{cm}^{3}$ in the samples. The specimens were prepared by pouring the cementsand mixture containing $10 \%$ water into a compacting cylinder and applying 25 blows per layer. The compaction was performed in five even layers, and each layer was scarified to allow good bonding between them. The samples were demoulded after $1 \mathrm{~d}$ and cured for $7 \mathrm{~d}$ in a humidity cabinet in accordance with the standard practice for a cementstabilised material.

The SM, SCM, SC and SC65 samples were prepared as follows. Where required, cement was added at a proportion of $7 \%$ (by mass) of sand. Water was added at a proportion of $10 \%$ (by mass) to the SC and SC65, while bacterial solution was added in lieu of water at a proportion of $10 \%$ (by mass) to the SCM and SM samples. The samples were compacted to a MDD of $1.6 \mathrm{~g} / \mathrm{cm}^{3}$. Following compaction, cementation solution was added daily to the MICP-treated samples, while water was added to the control samples, as described in Section 2.1.



Figure 1. Particle size distribution 
The RC and RCM samples were prepared as follows. Cement was added at a proportion of $5 \%$ (by mass) of road base material. Water was added at a proportion of $12 \%$ to achieve a MDD of $2 \mathrm{~g} / \mathrm{cm}^{3}$. The bacterial solution was added in lieu of water at a proportion of $12 \%$ (by mass) to the RCM samples. For non-cement-stabilised samples (R and RM), water or bacterial solution was added at a proportion of $11 \%$ to achieve a MDD of $2 \mathrm{~g} / \mathrm{cm}^{3}$. Following compaction, cementation solution was added daily to the MICP-treated samples while water was added to the control samples, as described in Section 2.1.

\subsection{Compressive strength testing}

After the end of the curing period, the specimens were tested for UCS. Testing was performed on a universal testing machine (Shimadzu AGS-X) in accordance with AS 5101.4 (SA, 2008). The specimens were placed vertically on the bottom plate. A digital camera was mounted in front of the specimen and snapshots were taken at regular intervals while compressing the sample at a rate of $1 \mathrm{~mm} / \mathrm{min}$. Open source DIC Matlab software (NCorr) was used to trace twodimensional displacement and strains throughout the deformation process.

\subsection{SEM and EDS}

After UCS testing, SEM and EDS analyses were undertaken on small portions of the samples. Samples were mounted on aluminium stubs and coated with a $10 \mathrm{~nm}$ thick carbon coating. SEM images and EDS were taken with a Zeiss Neon 40EsB dual beam field emission scanning electron microscope (FESEM)/focused ion beam (FIB)-SEM.

\subsection{Nanoindentation testing}

Nanoindentation testing was conducted on samples SM, SC and SCM in order to gain a deeper understanding of the mechanical properties of the samples at the microscopic level. Nanoindentation was undertaken using a G200 Agilent Technologies nanoindenter.

The samples were mounted in epoxy resin and allowed to cure for a period of $24 \mathrm{~h}$. After curing, the samples were ground back and polished using a Buehler EcoMet grinder polisher. Locations for nanoindentation were manually selected using a $40 \times$ optical microscope fitted to the nanoindenter. Selected locations for nanoindentation were on the sand grain, on the bridge between grains, on the sand grain/bridge interface and on the epoxy resin. A minimum of 100 indentations was undertaken on each location type for each sample. The samples were indented to a depth of $1000 \mathrm{~nm}$ using a Berkovich diamond tip at a loading rate of $0.5 \mathrm{mN} / \mathrm{s}$. The indenter was controlled with Testworks 4 (version 4.10) (MTS System Corporation) using an allowable drift rate of 0.3 and a surface approach distance of $2000 \mathrm{~nm}$. A Poisson's ratio of 0.3 was assumed for the purpose of calculating the modulus and hardness. Modulus and hardness calculations were performed based on the load-indentation curves utilising NanoTest Platform Four V40.08 software (Micro Materials Ltd).

\section{Results and discussion}

\subsection{Scale effect and impact of MICP treatment on compaction}

The results of the control cylinders of three length scales are shown in Figure 2. They indicate an increase in strength with increasing cylinder size. Although smaller scale usually increases strength, a reverse trend was observed here due to the difference in compaction. SC100 was fully compacted at the OMC. However, in SC65, the addition of fluid during the curing process changed the moisture conditions. There was a marginal reduction in compressive strength due to lack of compaction. In the case of SC, the OMC also could not be maintained. In fact, in this case, the specimens were supersaturated. As a result, the strength decreased by nearly $25 \%$. It is known that soil expands in volume due to the buoyancy effect under supersaturated conditions. Thus, the void space in soil is increased, resulting in a reduction in strength. These results also indicate that it may be wise to devise MICP techniques with frugal water content where saturation can be avoided. The results for the SC samples were used to determine the effect of MICP on UCS (Figure 2).

\subsection{Compressive strength}

The effect of MICP on sand and road base samples is now reported. The stress-strain curves for sand stabilised with only MICP are shown in Figure 3(a) while the stress-strain curves for cement-stabilised sand with and without MICP treatment

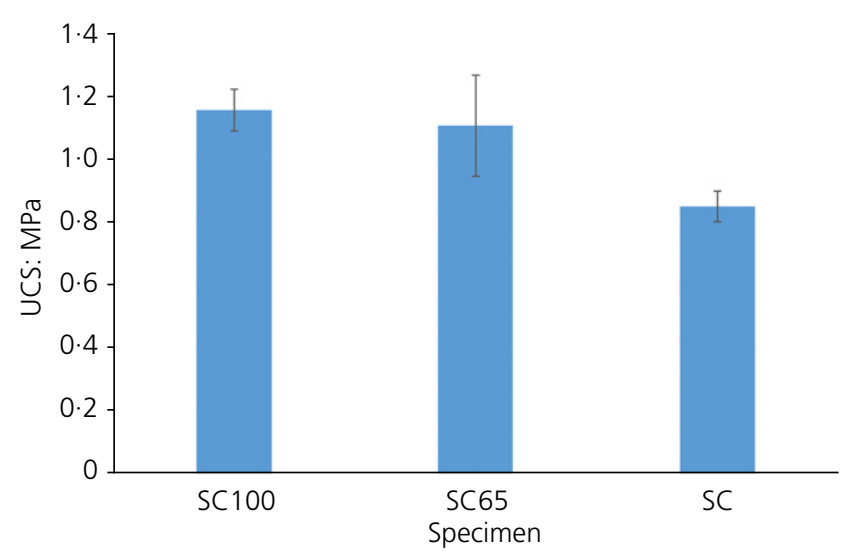

Figure 2. UCSs of samples of varying size 




(a)

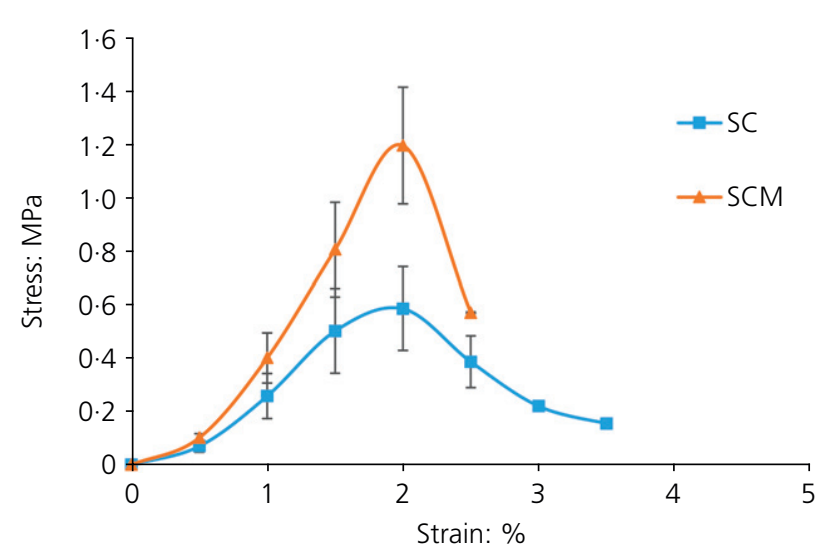

(b)

Figure 3. Stress-strain curves for stabilised sand samples: (a) SM; (b) SC and SCM the error bars. In the case of the combined cement and MICPstabilised samples (SCM), a significant improvement in strength (of the order of $50 \%$ ) was observed due to MICP, far greater than the strength improvement achieved in the samples treated using MICP only (SM). The underlying reason for such a dramatic improvement in strength will be discussed later through microstructural analysis and nanoindentation testing. The strain at the maximum load remained similar (2\%). All except one SC and one SCM sample collapsed at around 3\% strain.

It may be recalled that the road base samples had a wider grain size distribution than sand, with the presence of both finer and coarser particles. A significant improvement in strength was also recorded in the road base samples. The performance of MICP in road bases is reported here for the first time. Road base materials, ostensibly due to the presence of



Figure 4. Stress-strain curves for road base samples R and RM

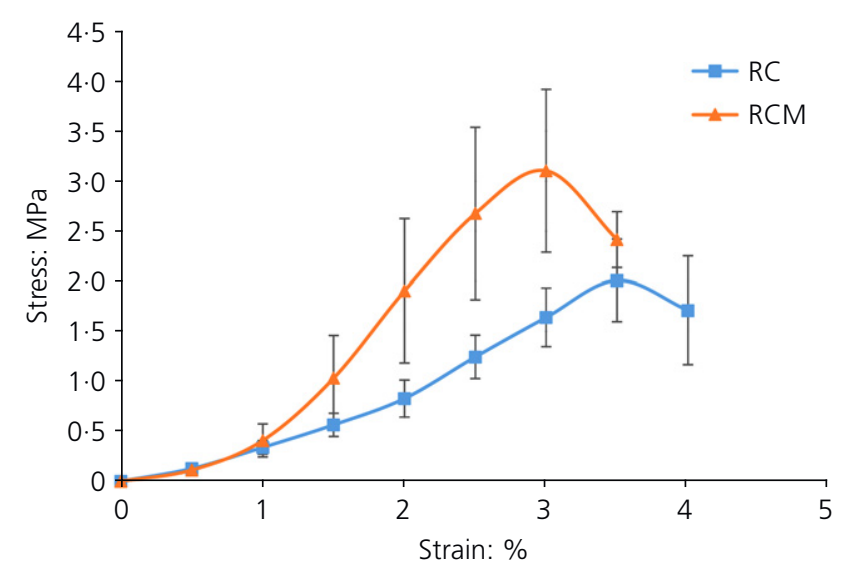

Figure 5. Stress-strain curves for road base samples RC and RCM

clay, aggregate without a binder. Therefore, their load capacities without binders were tested (Figure 4). They had an average strength of $0.3 \mathrm{MPa}$ at $2.5 \%$ strain $(\mathrm{R})$. When they were treated with MICP (RM), there was a dramatic (threefold) increase in strength. The load capacity reached $0.9 \mathrm{MPa}$ at $3 \%$ strain. However, the unloading portion of the curve was shorter. Clearly, MICP can bind road base materials well.

It may be recalled that, in the case of sand, there was a dramatic increase in strength when cement and MICP were used simultaneously (Figure 3). The performance of road base materials is shown in Figure 5. It can be noted that the cemented road base material had a load capacity of around $2 \mathrm{MPa}$ at a strain of $3 \cdot 5 \%$. Clearly, the stabilised road base material had a much higher load capacity than sand alone. This is due 




Figure 6. Secant moduli of sand and road base samples

to the wider grain size distribution of the road base, which leads to better packing and compaction. However, more compacted material may pose a challenge for MICP as the pores act as channels for the flow of cementation fluid. Figure 5 shows that the RCM samples had a load capacity of $3.6 \mathrm{MPa}$, which was an $80 \%$ improvement. However, the strain at maximal load was reduced to $3 \%$. There was a reduction in the ultimate strain from $4 \%$ to $3 \cdot 5 \%$. Thus, MICP increases the strength and effective stiffness of cemented road bases.

Secant moduli for sand and road base samples with and without MICP were calculated from the stress-strain graphs by joining the origin with the point of maximum stress and measuring its slope. The secant moduli are shown in Figure 6. It may be noted that a column of loose sand would have no stiffness. When it is stabilised, it gains stiffness. Thus, the secant modulus is a measure of the degree of cementation achieved. A comparison between SC and SCM shows that the secant modulus increased at least twofold due to the MICP. This is a huge increase considering that only a small percentage of carbonate deposition is expected from the MICP. The road base samples $(\mathrm{R})$ had a small stiffness (10 MPa). When they were stabilised with MICP, the modulus of the samples (RM) increase by three times (30 MPa). When they were stabilised with cement (RC), the modulus was a little above $60 \mathrm{MPa}$. However, when they were further treated with MICP (RCM), the modulus rose nearly twofold again to above $120 \mathrm{MPa}$. Thus, MICP stabilises road base material very effectively and it also reinforces cement-stabilised road base materials to a great extent.

Evidently, MICP can offer a huge benefit in reducing cement consumption in road bases, and can thus improve both economic and environmental sustainability. As mentioned previously, the cost of binder materials in stabilisation works can be equivalent to or more than $40 \%$ of the total cost of the stabilisation works (Austroads, 2006), while the embodied energy in the cement binder $(5000 \mathrm{MJ} / \mathrm{t})$ is overwhelmingly the largest component in stabilised road base works (Austroads, 2007). The use of MICP has a great potential to turn around the sustainability challenges faced by the Australian road industry. However, these are early results and the authors are aware that several breakthroughs are imperative for successful field implementation of the technology.

\subsection{Microstructural investigation}

Microstructural analysis was undertaken to reveal the cause of the dramatic increase in the UCS and modulus due to MICP. SEM coupled with EDS was used to possibly identify the sand grains, the hydrated cement and the calcium carbonate particles. Figure 7 illustrates a typical micrograph with the EDS of SM (sand stabilised with MICP). The sand is identified by the abundance of silicon and oxygen in the EDS while the calcium carbonate crystals are identifiable through the presence of calcium. Clearly, the calcium carbonate deposit is bridging two sand particles.

SEM images revealed that carbonate deposits occurred at two locations: $(a)$ at the grooves on the sand grains (Figure 8(a)) and $(b)$ at the acute corners created by the contacting grains of sand (Figure 8(b)). This occurs because bacteria can securely attach themselves in those corners and are not easily dislodged. Their metabolic activity in those critical areas results in the nucleation and growth of calcium carbonate crystals. MICP can therefore reinforce a material by preventing inter-granular slip or rotation and building bridges between sand grains. Thus, it creates a topologically optimal configuration of

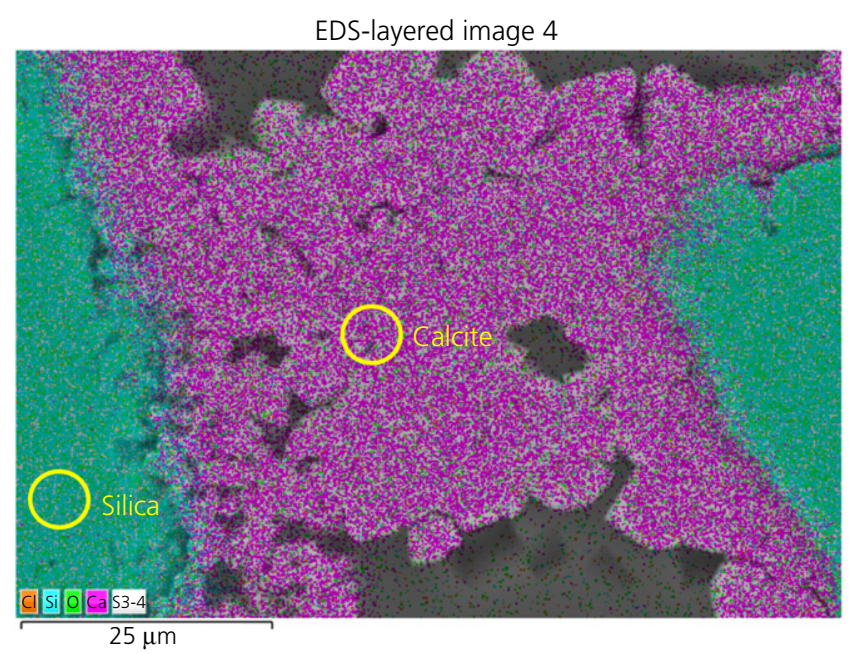

Figure 7. Typical EDS micrograph of calcium carbonate crystals attached to sand particle 


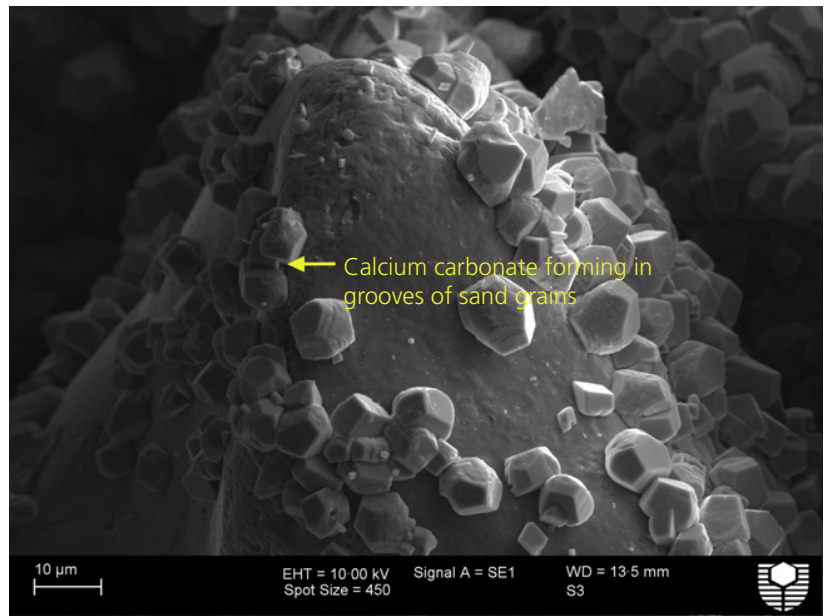

(a)

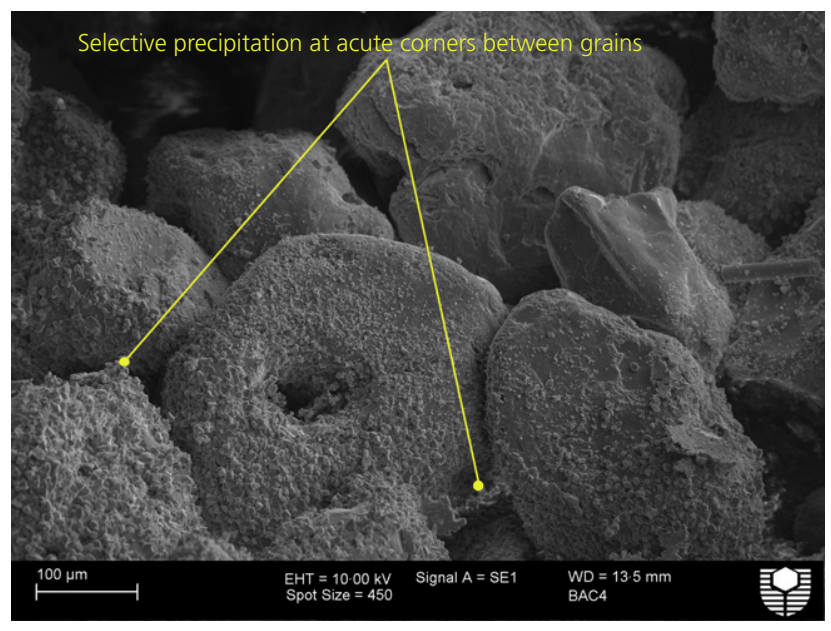

(b)

Figure 8. (a) Crystal formation in rough areas of sand grains and (b) carbonate bridging at acute corners between sand grains

cementation. Cement, on the other hand, coats the grains more evenly and thus only a fraction of it is effective in binding the particles. In the case of cement-stabilised sand with MICP, cement was observed coating the sand grains while rhombohedral crystals were observed reinforcing the bridges between grains (Figure 9).

Figure 10(a) shows EDS results taken at a bridge between particles (Figure 9). Peaks of calcium and oxygen are indicative of calcium carbonate precipitation. Figure 10(b) shows the EDS results of the cement particles coating the sand grains. Silica is indicative of the sand grains while potassium, aluminium, sodium and calcium are typical peaks observed in cement. Figure 10(c) shows a typical spectrum of the sand grain, with peaks of silica and oxygen.

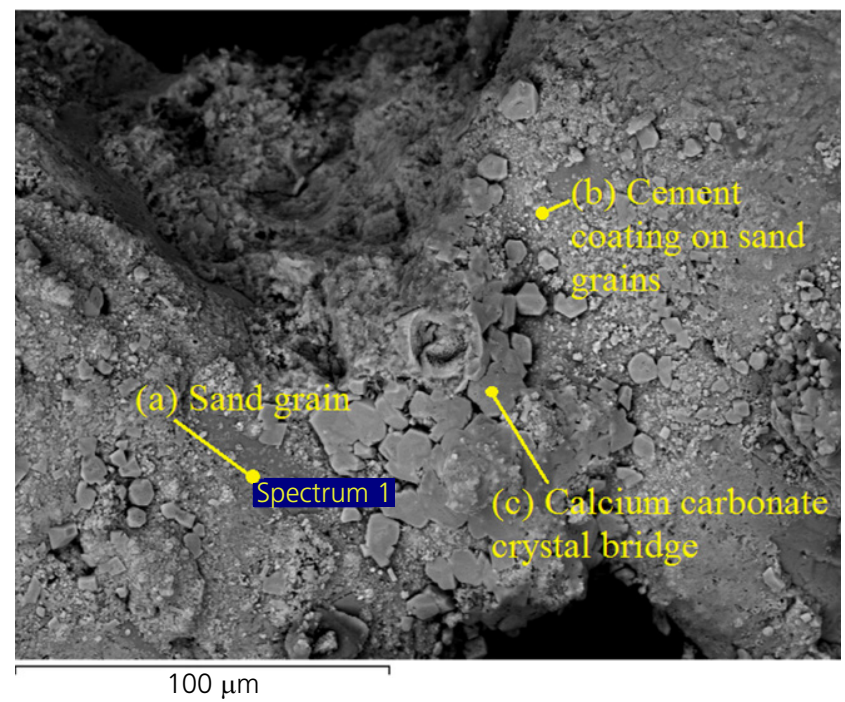

Figure 9. SEM micrograph of cement-stabilised + MICP-treated sand

\subsection{Nanoindentation testing}

To estimate the relative bond strengths between the binder and the sand, nanoindentation testing was performed on samples SC, SM and SCM. Nanoindentation allows evaluation of mechanical properties on a microscopic scale. Thus, it is possible to evaluate the components individually as well as the interfacial transition zone. Of special interest in this investigation were the mechanical properties of cement bonding, MICP bonding and a combined MICP-cement bonding system. Previous studies have demonstrated the microscopic mechanical properties of calcium carbonate crystals with differing morphologies (Dhami et al., 2016b; Merkel et al., 2009; Muller et al., 2014; Ren et al., 2013). However, information regarding the mechanical performance of crystals precipitated within a granular soil structure has been unavailable hitherto. This paper reports the performance of cement, MICP and a combined cement-MICP stabilising system. Indentations were undertaken on the sand grain, on the bridges between particles and on the grain-bridge interface. An example of nanoindentation locations on the bridge and bridge interface is shown in Figure 11.

Typical load-indentation curves for the samples are shown in Figure 12. It can be seen that the components sand, binder and the holding epoxy had very distinct load-indentation responses. Therefore, correlation of the response with the location of the indentation was simple. Sand was the hardest component, followed by the cement, and the epoxy had an order of magnitude lower stiffness. Thus, the epoxy is unlikely to influence the results. The interface had a stiffness 




(a)

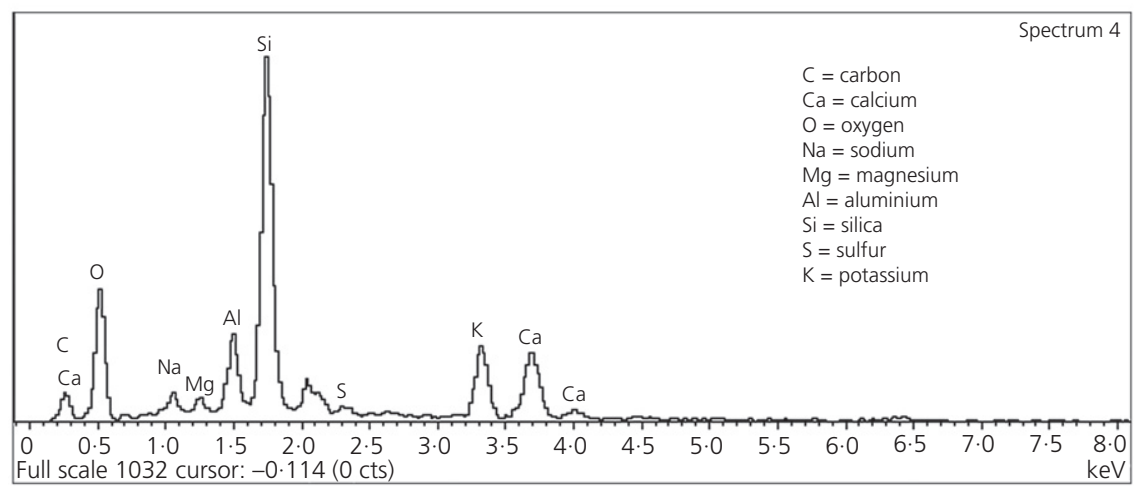

(b)



(c)

Figure 10. EDS results of cement-stabilised + MICP-treated sand at different locations: (a) sand particles; (b) cement coating on sand grains; (c) calcium carbonate bridge

comparable to, but always less than, that of the cement. A summary of the average modulus and hardness obtained from all the indentations is given in Table 4 . The average modulus and hardness results for precipitated calcium carbonate crystals in sample SM are similar to previously published results (Dhami et al., 2016b; Ren et al., 2013). Dhami et al. (2016b) report a modulus of $64.50 \pm 2.7$ and a hardness of $3.92 \pm 0.43$ for pure calcium carbonate crystals precipitated using S. pasteurii (ATCC 11859). This proves that the mechanical properties of the carbonate crystals deposited in road base materials are similar to those obtained in a flask.

In the case of samples treated only with MICP (SM) or with cement (SC), the modulus results for the interlocking bridge 
Sustainable road bases with

microbial precipitation

Porter, Dhami and Mukherjee



(a)



(b)

Figure 11. Typical location of indents (sample SM): (a) on bridge; (b) on interface



(a)

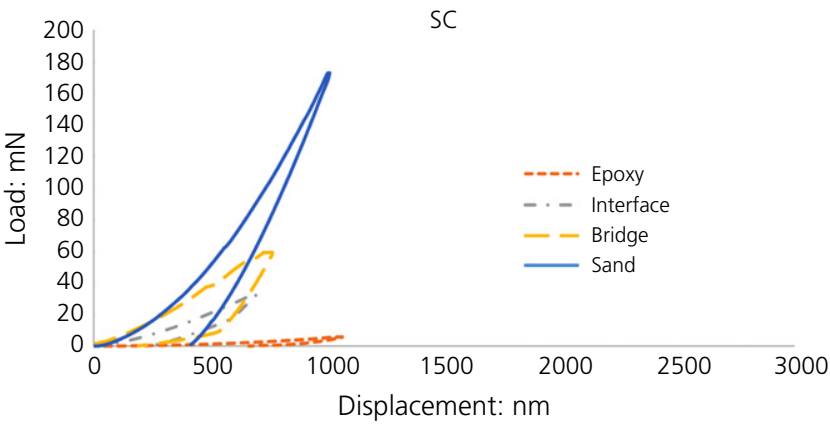

(b)

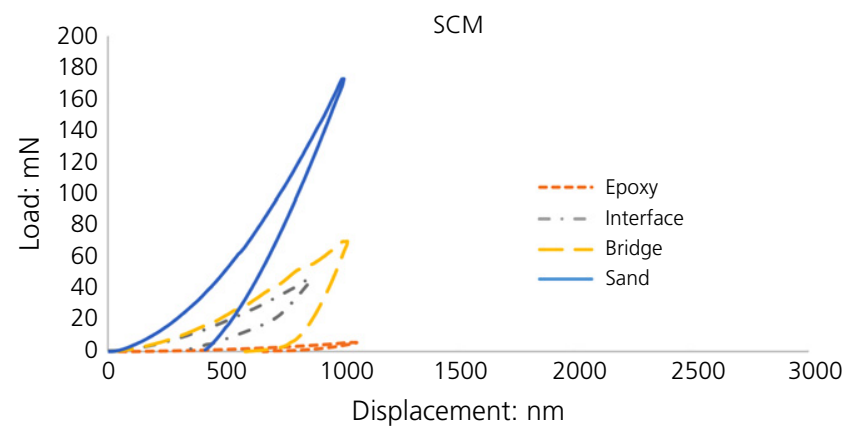

(c)

Figure 12. Typical load-indentation curves: (a) SM; (b) SC; (c) SCM

Table 4. Mechanical properties obtained from nanoindentation testing

\begin{tabular}{|c|c|c|c|c|c|}
\hline Sample & Location & Modulus: GPa & Std. error & Hardness: GPa & Std. error \\
\hline \multirow[t]{4}{*}{ SM } & Sand grain & $118 \cdot 64$ & 1.00 & $16 \cdot 79$ & 0.18 \\
\hline & Epoxy & $4 \cdot 25$ & 0.07 & $0 \cdot 34$ & 0.008 \\
\hline & Bridge (calcium carbonate) & $77 \cdot 07$ & $4 \cdot 17$ & $7 \cdot 67$ & 0.77 \\
\hline & Bridge-grain interface & $54 \cdot 72$ & $2 \cdot 49$ & 4.93 & 0.45 \\
\hline \multirow[t]{2}{*}{ SC } & Bridge (cement) & $74 \cdot 32$ & $2 \cdot 27$ & $3 \cdot 53$ & $0 \cdot 36$ \\
\hline & Bridge-grain interface & $35 \cdot 44$ & $1 \cdot 18$ & $5 \cdot 00$ & 0.08 \\
\hline \multirow[t]{2}{*}{ SCM } & Bridge (calcium carbonate + cement) & $84 \cdot 58$ & $7 \cdot 61$ & $9 \cdot 39$ & $1 \cdot 15$ \\
\hline & Bridge-grain interface & $64 \cdot 25$ & $2 \cdot 74$ & $5 \cdot 66$ & 0.43 \\
\hline
\end{tabular}




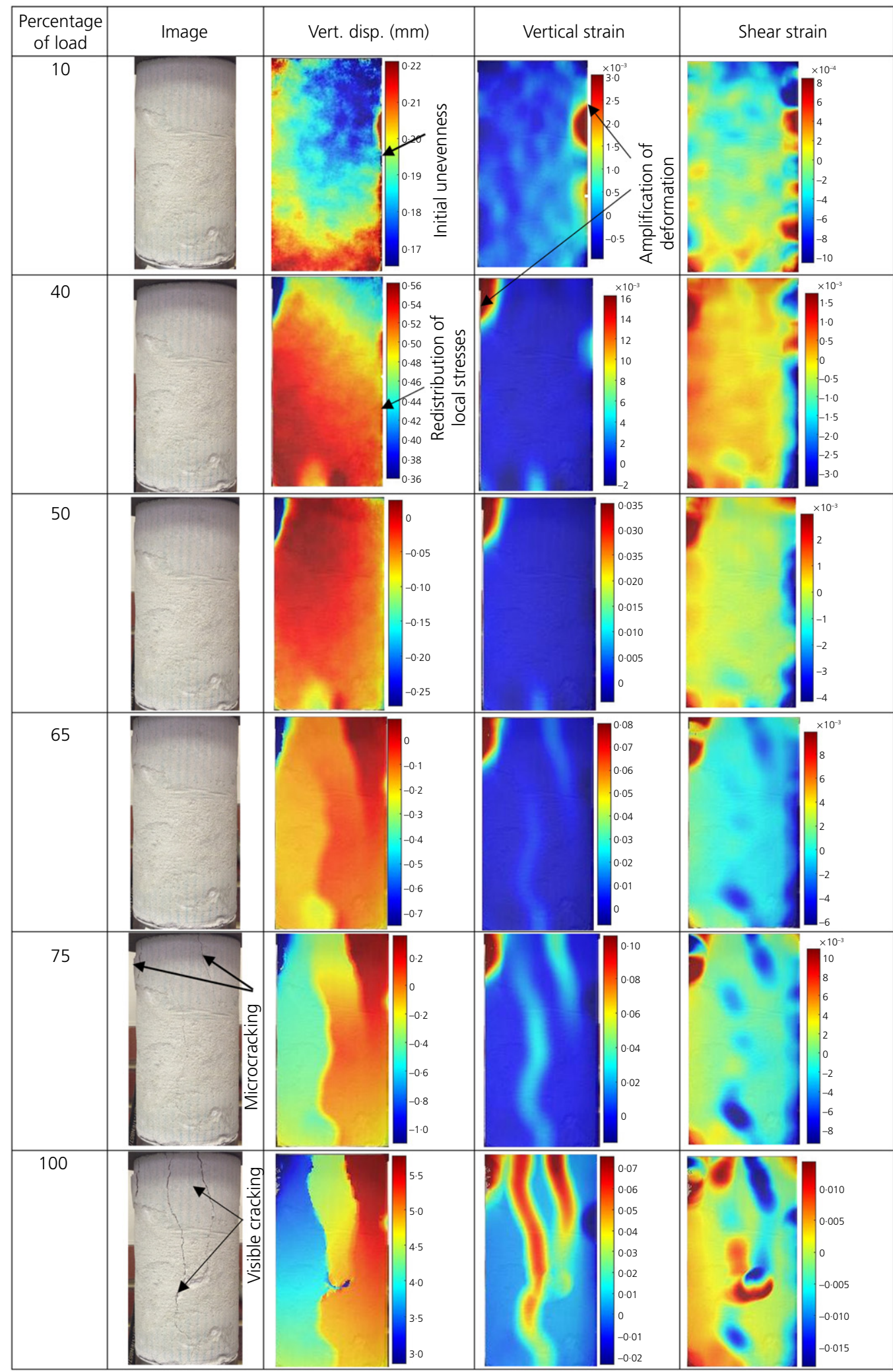

Figure 13. DIC results at varying loads 
structures were similar (77.07 and $74.32 \mathrm{GPa}$, respectively) However, when the cementitious systems were combined (SCM), the modulus of the bridge structures increased by $\sim 9 \%$.

The modulus results obtained for the interface between the bridge and sand grain were consistently lower than the modulus results obtained on the bridge itself. In the case of the cement-stabilised samples (SC), the average modulus was $35 \%$ lower than that obtained on the cement bridges. In the case of MICP-stabilised samples (SM), the average modulus at the interface was $29 \%$ lower than that obtained on the bridges between grains, while for the combined MICP/cement system the average modulus at the interface was $24 \%$ lower than that obtained on the bridges.

UCS testing revealed that when MICP treatment was performed on cementitiously stabilised samples, the increase in strength due to MICP was significantly higher than that obtained when MICP treatment was applied to unstabilised samples. SEM imaging of these samples revealed that, in the combined system, the cement evenly coated the sand grains while the MICP crystals were likely to precipitate at the bridges between grains, providing a higher degree of reinforcement at the bridges and resulting in a higher overall compressive strength. The results obtained from nanoindentation testing demonstrated that, in the case of cement-stabilised specimens treated with MICP, the stiffness of the bridges between the particles and the bridge-grain interface was increased due to the precipitation of calcium carbonate at these locations.

\subsection{DIC analysis}

To gain a deeper understanding of the failure modes of the stabilised samples, DIC analysis was performed. The opensource Matlab software NCorr was used for DIC analysis. Photographs were taking during UCS testing for this purpose. Figure 13 shows the DIC results for a standard specimen stabilised with $3 \%$ cement. Three parameters (vertical displacement, vertical strain and shear strain) are shown at varying load steps throughout the UCS test. The results of the DIC analysis effectively show the variation of strain and deformation in the sample at a much more detailed level than has typically been available through the use of strain gauges. At $10 \%$ of the total load, no damage to the specimen is visible; however, the displacement graph shows local stresses down the side of the specimen that are amplified in the strain graphs. At $50 \%$ of the total load, these local stresses have disappeared, likely due to the localised redistribution of grains. At $40 \%$ of the total load (prior to any visible cracking), the origin of cracking is observable in both the vertical strain and vertical displacement graphs. At $65 \%$ of the total load, the propagation of cracking is visible in the vertical displacement and vertical strain plots before the cracks can be visibly observed in the specimen. At $100 \%$ of the total load, both the vertical displacement and vertical strain graphs accurately map the crack locations. The results of this experiment indicate the potential of DIC to identify the location of cracking in a stabilised material before it becomes visible. The use of DIC in the field may have significant benefits for asset management, allowing the identification of areas of failure and early remedial actions prior to substantial damage to an asset (Figure 13).

\section{Conclusion}

The investigations reported in this paper aimed to determine the strength improvements that can be obtained by combining cement stabilisation with MICP. The key conclusions made from this investigation are as follows.

- It is important to consider the scale effect of samples when comparing the performance of MICP and conventional stabilisation.

- The saturation of soil due to MICP affects its compaction and UCS. An MICP technique that allows reduction of water to the OMC level would be extremely beneficial.

- MICP can be successfully used to improve the strength of cement-stabilised sand and road base materials as well as a plain, compacted road base. In the case of plain road base materials, treatment with MICP resulted in a 70\% increase in UCS, providing values consistent with that required for a modified road base material. In the case of cement-stabilised road base and sand materials, MICP treatment resulted in an increase of between 33 and 50\%. In cement-stabilised samples, MICP improved the strength by reinforcing the bridging structures between grains and the bridge/sand grain interface. These results demonstrate that MICP may be used as a supplementing material in stabilised soil structures, reducing the overall requirements for cement, thereby increasing the sustainability of such materials. MICP may also be useful for rehabilitation works on cement-stabilised pavement structures.

- DIC can be successfully used to observe the degradation process of cement-stabilised materials. The use of both displacement and strain maps from DIC can provide an indication of where cracking is going to occur and may provide a useful asset-management tool for road surfaces.

\section{Acknowledgements}

The authors would like to acknowledge the Department of Transport and Main Roads, West Australia for the provision of the road base material utilised as part of this investigation. The authors also acknowledge the use of Curtin University's 
Microscopy \& Microanalysis Facility, whose instrumentation has been partially funded by the University and State and Commonwealth Governments.

\section{REFERENCES}

Achal V and Mukherjee A (2015) A review of microbial precipitation for sustainable construction. Construction and Building Materials 93: 1224-1235, https://doi.org/10.1016/j.conbuildmat.2015.04.051.

Achal V, Mukherjee A, Basu PC and Reddy MS (2009a) Strain improvement of Sporosarcina pasteurii for enhanced urease and calcite production. Journal of Industrial Microbiology and Biotechnology 36(7): 981-988.

Achal V, Mukherjee A, Basu PC and Reddy MS (2009b) Lactose mother liquor as an alternative nutrient source for microbial concrete production by Sporosarcina pasteurii. Journal of Industrial Microbiology and Biotechnology 36(3): 433-438.

Achal V, Mukherjee A, Kumari D and Zhang Q (2015) Biomineralization for sustainable construction - a review of processes and applications. Earth-Science Reviews 148: 1-17, https://doi.org/ 10.1016/j.earscirev.2015.05.008.

Austroads (Australasian Road Transport and Traffic Authority) (2006) Austroads Guide to Pavement Technology Part 4D: Stabilised Materials. Austroads, Sydney, NSW, Australia.

Austroads (2007) Austroads Guide to Pavement Technology: Part 4: Pavement Materials. Austroads, Sydney, NSW, Australia.

Bains A, Dhami NK, Mukherjee A and Reddy MS (2015) Influence of exopolymeric materials on bacterially induced mineralization of carbonates. Applied Biochemistry and Biotechnology 175(7) 3531-3541.

Bergdale TE, Pinkelman RJ, Hughes SR et al. (2012) Engineered biosealant strains producing inorganic and organic biopolymers. Journal of Biotechnology 161(3): 181-189.

Bernardi D, DeJong JT, Montoya BM and Martinez BC (2014) Bio-bricks: biologically cemented sandstone bricks. Construction and Building Materials 55: 462-469, https://doi.org/10.1016/j.conbuildmat.2014. 01.019 .

Burbank MB, Weaver TJ, Green TL, Williams BC and Crawford RL (2011) Precipitation of calcite by indigenous microorganisms to strengthen liquefiable soils. Geomicrobiology Journal 28(4): 301-312.

Castanier S, Le Métayer-Levrel G and Perthuisot JP (1999) Ca-carbonates precipitation and limestone genesis - the microbiogeologist point of view. Sedimentary Geology 126(1): 9-23.

Chen PY, McKittrick J and Meyers MA (2012) Biological materials: functional adaptations and bioinspired designs. Progress in Materials Science 57(8): 1492-1704.

Chu J, Stabnikov V and Ivanov V (2012) Microbially induced calcium carbonate precipitation on surface or in the bulk of soil. Geomicrobiology Journal 29(6): 544-549.

DeJong JT, Mortensen BM, Martinez BC and Nelson DC (2010) Bio-mediated soil improvement. Ecological Engineering 36(2): 197-210.

DeJong JT, Martinez BC, Ginn TR et al. (2014) Development of a scaled repeated five-spot treatment model for examining microbial induced calcite precipitation feasibility in field applications. Geotechnical Testing Journal 37(3): 424435.

Dhami N, Reddy M and Mukherjee A (2012a) Biofilm and microbial applications in biomineralized concrete. In Advanced Topics in Biomineralization (Seto J (ed.)). InTech, Patiala, India, pp. $137-164$
Dhami NK, Reddy MS and Mukherjee A (2012b) Improvement in strength properties of ash bricks by bacterial calcite. Ecological Engineering 39(1): 31-35.

Dhami NK, Reddy MS and Mukherjee A (2016a) Significant indicators for biomineralisation in sand of varying grain sizes. Construction and Building Materials 104: 198-207, https://doi.org/10.1016/ j.conbuildmat.2015.12.023.

Dhami NK, Mukherjee A and Reddy MS (2016b) Micrographical, minerological and nano-mechanical characterisation of microbial carbonates from urease and carbonic anhydrase producing bacteria. Ecological Engineering 94(1): 443-454.

DoIRD (Department of Infrastructure and Regional Development) (2015) Australian infrastructure statistics. In Development. DoIRD, BITRE, Canberra, Australia, Chapter 4, pp. 44-46.

Ercole C, Bozzelli P, Altieri F, Cacchio P and Del Gallo M (2012) Calcium carbonate mineralization: involvement of extracellular polymeric materials isolated from calcifying bacteria. Microscopy and Microanalysis 18(4): 829-839.

Ferris FG, Stehmeier LG, Kantzas A and Mourits FM (1996) Bacteriogenic mineral plugging. Journal of Canadian Petroleum Technology 35(8): 56-61.

Harkes MP, Van Paassen LA, Booster JL, Whiffin VS and Van Loosdrecht MCM (2010) Fixation and distribution of bacterial activity in sand to induce carbonate precipitation for ground reinforcement. Ecological Engineering 36(2): 112-117.

ISO (International Organization for Standardization) (2002) ISO14688-1: Geotechnical investigation and testing - identification and classification of soil. Part 1: identification and description. ISO, Geneva, Switzerland.

Le Métayer-Levrel G, Castanier S, Orial G, Loubière JF and Perthuisot JP (1999) Applications of bacterial carbonatogenesis to the protection and regeneration of limestones in buildings and historic patrimony. Sedimentary Geology 126(1): 25-34.

Merkel C, Deuschle J, Griesshaber E et al. (2009) Mechanical properties of modern calcite- (Mergerlia truncata) and phosphate-shelled brachiopods (Discradisca stella and Lingula anatina) determined by nanoindentation. Journal of Structural Biology 168(3): 396-408.

Mitchell JK and Santamarina JC (2005) Biological considerations in geotechnical engineering. Journal of Geotechnical and Geoenvironmental Engineering 131(10): 1222-1233.

Muller WEG, Neufurth M, Schlossmacher U et al. (2014) The sponge silicatein-interacting protein silintaphin-2 blocks calcite formation of calcareous sponge spicules at the vaterite stage. RSC Advances 4(6): 2577-2585.

Okyay TO and Rodrigues DF (2015) Biotic and abiotic effects on $\mathrm{CO}_{2}$ sequestration during microbially-induced calcium carbonate precipitation. FEMS Microbiology Ecology 91(3): 1-13.

Ramachandran S, Ramakrishnan V and Bang S (2001) Remediation of concrete using microorganisms. ACI Materials Journal 98(1): 3-9.

Ren D, Meyers MA, Zhou B and Feng Q (2013) Comparative study of carp otolith hardness: lapillus and asteriscus. Materials Science and Engineering: C 33(4): 1876-1881.

SA (Standards Australia Limited) (2003) AS 1289.5.2.1: Methods of testing soils for engineering purposes. Method 5.2.1: soil compaction and density tests - determination of the dry density/moisture content relation of a soil using modified compactive effort. SA, Sydney, NSW, Australia.

SA (2008) AS 5101.4: Methods for preparation and testing of stabilised materials. Method 4: unconfined compressive strength of compacted materials. SA, Sydney, NSW, Australia.

SA (2009) AS 1289.3.6.1: Soil classification tests - determination of the particle size distribution of a soil - standard method of analysis by 
sieving. Methods of testing soils for engineering purposes. SA, Sydney, NSW, USA.

SA (2010) AS 3972: General purpose and blended cements. SA, Sydney, NSW, Australia.

Stocks-Fischer S, Galinat J and Bang S (1999) Microbiological precipitation of $\mathrm{CaCO}_{3}$. Soil Biology Biochemistry 31(11): 1563-1571.

Van Paassen LA, Harkes MP, Van Zwieten GA et al. (2009) Scale up of BioGrout: a biological ground reinforcement method. In 17th International Conference on Soil
Mechanics and Geotechnical Engineering, Alexandrina, Egypt (Hamza M, Shahien M and El-Mossallamy Y (eds)). IOS Press, Amsterdam, the Netherlands, pp. 2328-2333.

Van Paassen LA, Daza CM, Staal M et al. (2010) Potential soil reinforcement by biological denitrification. Ecological Engineering 36(2): 168-175.

Whiffin VS, Van Paassen LA and Harkes MP (2007) Microbial carbonate precipitation as a soil improvement technique. Geomicrobiology Journal 24(5): 417-423.

\section{How can you contribute?}

To discuss this paper, please email up to 500 words to the editor at journals@ice.org.uk. Your contribution will be forwarded to the author(s) for a reply and, if considered appropriate by the editorial board, it will be published as discussion in a future issue of the journal.

Proceedings journals rely entirely on contributions from the civil engineering profession (and allied disciplines). Information about how to submit your paper online is available at www.icevirtuallibrary.com/page/authors, where you will also find detailed author guidelines. 